\title{
Phase Transformations and Heat Treatments of Steels
}




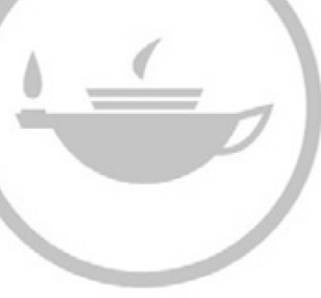

Tayllor \& Francis
Taylor \& Francis Group http://taylorandfrancis.com 


\section{Phase Transformations and Heat Treatments of Steels}

Bankim Chandra Ray, Rajesh Kumar Prusty, and Deepak Nayak

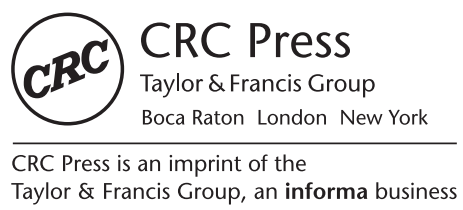


First edition published 2020

by CRC Press

6000 Broken Sound Parkway NW, Suite 300, Boca Raton, FL 33487-2742

and by CRC Press

2 Park Square, Milton Park, Abingdon, Oxon, OX14 4RN

(๑) 2020 Taylor \& Francis Group, LLC

CRC Press is an imprint of Taylor \& Francis Group, LLC

Reasonable efforts have been made to publish reliable data and information, but the author and publisher cannot assume responsibility for the validity of all materials or the consequences of their use. The authors and publishers have attempted to trace the copyright holders of all material reproduced in this publication and apologize to copyright holders if permission to publish in this form has not been obtained. If any copyright material has not been acknowledged, please write and let us know so we may rectify in any future reprint.

Except as permitted under U.S. Copyright Law, no part of this book may be reprinted, reproduced, transmitted, or utilized in any form by any electronic, mechanical, or other means, now known or hereafter invented, including photocopying, microfilming, and recording, or in any information storage or retrieval system, without written permission from the publishers.

For permission to photocopy or use material electronically from this work, access www.copyright. com or contact the Copyright Clearance Center, Inc. (CCC), 222 Rosewood Drive, Danvers, MA 01923, 978-750-8400. For works that are not available on CCC, please contact mpkbookspermissions@ tandf.co.uk

Trademark notice: Product or corporate names may be trademarks or registered trademarks and are used only for identification and explanation without intent to infringe.

ISBN: 978-0-367-02868-8 (hbk)

ISBN: 978-0-429-01921-0 (ebk)

Typeset in Times

by codeMantra 


\section{Contents}

Preface ix

Authors xi

Chapter 1 An Introduction to Metals ............................................................ 1

$1.1 \quad$ Elements, Atoms, and Isotopes ....................................... 1

1.2 Types of Bonding between Atoms........................................... 2

1.3 Crystal Structures ............................................................... 5

Further Reading ........................................................................ 19

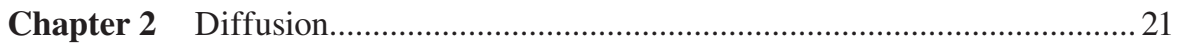

$2.1 \quad$ Atomic Diffusion Mechanisms ........................................... 21

2.2 Types of Diffusion ......................................................... 22

Further Reading ...................................................................... 36

Chapter 3 Defects in Crystalline Solids...................................................... 37

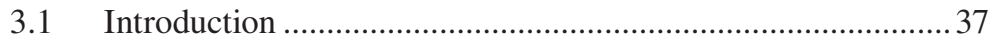

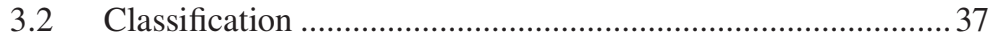

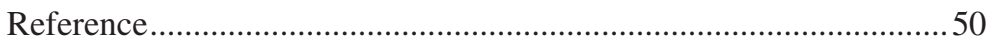

Further Reading .................................................................50

Chapter 4 Solid Solutions.......................................................................... 51

4.1 Introduction .................................................................. 51

4.2 Types of Solid Solutions ................................................. 51

4.3 Electron-to-Atom Ratio .................................................... 53

4.4 Enthalpy of Formation of a Solid Solution ...........................54

4.5 Entropy of Formation of a Solid Solution...............................56

4.6 Free Energy Change upon Formation of a Solid Solution....... 58

4.7 Ordered and Random Solid Solutions ..................................60

4.8 Intermediate Phases......................................................... 61

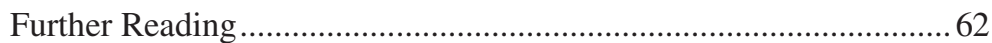

Chapter 5 Phase Diagrams and Phase Transformations ................................... 63

5.1 Thermodynamic Considerations of Phase Diagrams ............. 63

5.2 Gibb's Phase Rule ....................................................................64

5.3 Lever Rule ....................................................................6 65

5.4 Types of Phase Diagrams and Phase Transformations............66

5.5 Some Other Solid-Phase Transformations in

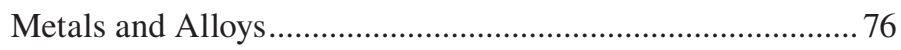


5.6 Roles of Defects and Diffusion ......................................... 77

Further Reading ................................................................. 78

Chapter 6 Iron-Carbon Phase Diagram ....................................................... 79

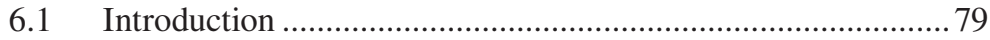

6.2 Allotropic Transformations in Iron .......................................8 80

6.3 Solubility of Carbon in Iron ................................................. 80

6.4 Iron-Iron Carbide Phase Diagram .....................................82

6.5 Effect of Alloying Elements on the

Iron-Carbon Equilibrium Diagram .................................... 86

Further Reading ................................................................... 90

Chapter 7 Thermodynamics and Kinetics of Solid-State Phase Transformation .....91

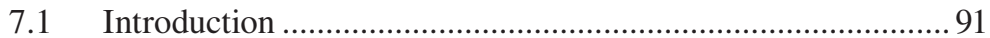

7.2 Nucleation.................................................................... 91

7.3 Growth Kinetics ........................................................... 98

7.4 Time-Temperature Transformation and Continuous

Cooling Transformation Diagrams..................................... 102

References ........................................................................... 106

Further Reading.................................................................... 106

Chapter 8 Phase Transformation in Steels .................................................... 107

$8.1 \quad$ Introduction ................................................................ 107

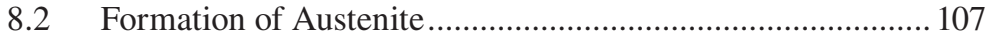

8.3 Pearlitic Transformation ................................................... 108

8.4 Bainitic Transformation.................................................... 111

8.5 Martensitic Transformation .............................................. 113

Further Reading ............................................................... 116

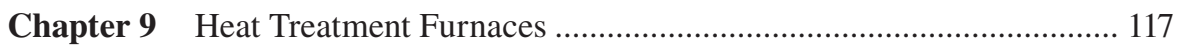

9.1 Introduction ................................................................... 117

9.2 Classification of Furnaces ............................................. 117

9.3 Batch Furnace ................................................................. 118

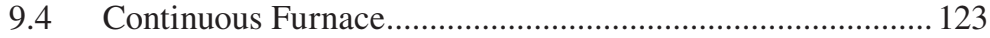

9.5 Salt Bath Furnace ......................................................... 125

Further Readings ................................................................. 125

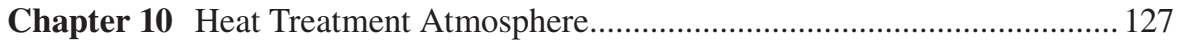

10.1 Introduction ............................................................... 127

10.2 Reactions between Atmosphere and Material ...................... 127

10.3 Types of Furnace Atmospheres ............................................. 129

Further Reading ........................................................................ 131 
Chapter 11 Common Heat Treatment Practices.............................................. 133

11.1 Introduction .................................................................. 133

11.2 Typical Heat Treatment Processes.................................... 133

11.3 Hardenability .............................................................. 153

11.4 Case Hardening and Surface Hardening ............................ 158

11.5 Thermomechanical Treatment............................................ 164

11.6 Heat Treatment of Carbon and Alloy Steels......................... 166

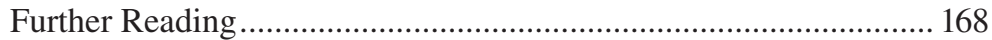

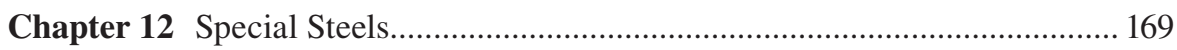

12.1 Stainless Steels .............................................................. 169

12.2 Hadfield Manganese Steels............................................... 172

12.3 High-Strength Low-Alloy or Microalloyed Steels ............... 172

12.4 Transformation-Induced Plasticity Steels........................... 172

12.5 Maraging Steels ............................................................... 173

12.6 Dual-Phase Steels ............................................................ 173

12.7 Tool Steels ................................................................... 173

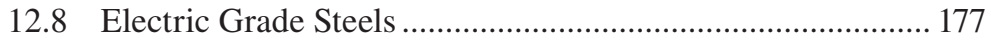

Further Reading .................................................................. 177

Chapter 13 Some In Situ Postweld Heat Treatment Practices .......................... 179

13.1 Necessity................................................................... 179

13.2 Conventional Postweld Heat Treatment Process ................... 179

13.3 In Situ Postweld Heat Treatment of TransformationInduced Plasticity Steel ....................................................... 180

13.4 Postweld Heat Treatment of Duplex Stainless Steel............. 182

References .......................................................................... 184

Chapter 14 Heat Treatment of Cast Iron ........................................................... 185

14.1 Introduction .............................................................. 185

14.2 Types of Cast Iron .......................................................... 185

14.3 Heat Treatment of Gray Cast Iron ...................................... 192

14.4 Heat Treatment of Malleable Cast Iron .................................. 193

14.5 Heat Treatment of Spheroidal Graphite Irons ..................... 194

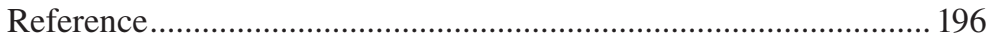

Further Reading ....................................................................... 196

Chapter 15 Heat Treatment Defects and Their Determination........................... 197

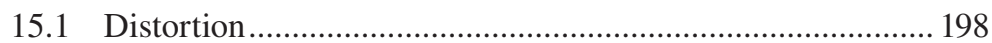

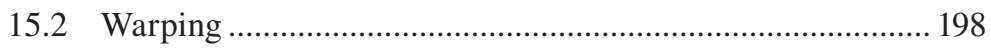

15.3 Residual Stresses .......................................................... 199

15.4 Quench Cracking .......................................................... 199 


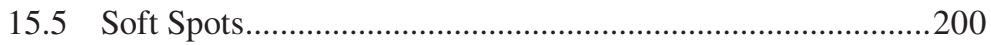

15.6 Oxidation and Decarburization ............................................ 201

15.7 Low Hardness and Strength after Hardening.......................202

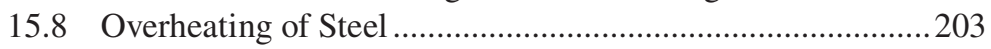

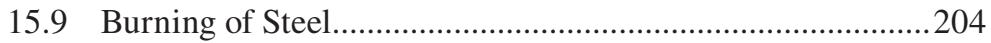

15.10 Black Fracture .................................................................205

15.11 Deformation and Volume Changes after Hardening .............205

15.12 Excessive Hardness after Tempering .................................. 205

15.13 Corrosion and Erosion .................................................206

References .........................................................................206

Further Reading .....................................................................206

Chapter 16 Some Special Heat Treatment Practices........................................207

16.1 Automobile Industries .....................................................207

16.2 Aerospace Industries ...................................................... 210

16.3 Medical Equipment ....................................................... 214

16.4 Defense Industries ........................................................ 216

References .................................................................. 217

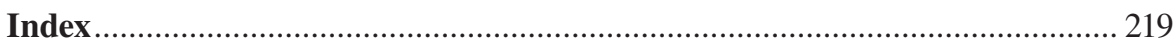




\section{Preface}

The study of phase transformations, in terms of subtly underlying thermodynamics and kinetics with the probability of attachment of atoms to critical nuclei, forms the scientific aspect of formation of microstructures, and subsequently, the practical practices of phase transformations are commercially achieved through heat treatments. As a matter of fact, heat treatment solely involves managing the kinetics of phase transformation to achieve desirable properties required in technological applications. This book explains mechanisms, thermodynamics, and kinetics of phase transitions in materials engineering field of steels and provides concepts to commercialization-oriented understanding of heat treatment practices and principles on the knowledge of phase transformations. Phase transformation and heat treatment are indeed connected concurrently and, in the authors' opinion, should be treated as complementary subjects as opposed to distinct subjects. Phase Transformations and Heat Treatments of Steels attempts to fill this gap, prevalent in the available literature. The book's unique presentation links basic understanding of theory with application in a perpetually progressive yet exciting manner.

The book focuses on the processing-structure-properties triangle/structureproperty correlation, as it introduces the fundamental principles of physical metallurgy, phase transformations, and heat treatments of steel legacy as a structural material. It supplies a broad overview of specific types of phase transformations, supplemented by practical case studies of engineering alloys. The lucid, well-organized, and eminently readable text not only provides a proficient analysis of all the relevant topics but also makes them comprehensible to the readers through the adept use of numerous diagrams and illustrations. The book takes a pedagogical approach and analyzes all concepts systematically and logically, making it ideal for those new to the field.

While attempting to provide a comprehensive understanding of phase transformations with the practice of heat treatment and their interrelationships, the authors have tried to provide insights into specialized processes and practices, and to convey the excitement of the atmosphere in which new and different properties are introduced and tailored.

Divided into 16 chapters, the material is organized in a logical progression, beginning with fundamental principles and then building to more complex concepts involved in phase transformation and heat treatment of almost all types of steels as well as cast irons.

The book begins with a clear exposition of the basic concepts and definitions related to metals, chemical bonding, and the structure of solids in Chapter 1. Chapters 2 and 3 provide a theoretical background to solid-state diffusion and crystal imperfections. These chapters also provide a deep insight into the structural control necessary for optimizing the various properties of materials. Then, a detailed discussion on solid solutions with their types and the associated thermodynamics follows in Chapter 4. The first part of Chapter 5 offers an in-depth analysis of phase diagrams, while the latter part covers the structure and change of structure through 
phase transformations. Chapter 6 discusses, in rich detail, the iron-carbon phase diagram, which is indispensable in the field of metallurgy and materials engineering. Chapter 7 emphasizes the thermodynamic and kinetic aspects of solid-state phase transformation. This includes a comprehensive discussion on nucleation and growth in the context of phase transformations in general. Chapter 8 extends the theory of phase transformations to steels. Chapter 9 provides succinct summaries of common furnaces used for heat treatment. This is followed by a thorough discussion on heat treatment atmosphere in Chapter 10. Chapter 11 is devoted to a detailed description of the prevalent heat treatment practices and their purposes. It also highlights the topics of hardenability, hardening treatment, and thermomechanical treatment. Chapter 12 introduces certain special steels in order to pique readers' interest for understanding the current and futuristic aspects of steels application. Chapters 13 and 14 describe in situ postweld heat treatment practices and heat treatments of cast irons, respectively. Chapter 15 is dedicated to discussing defects produced due to heat treatment and their characterization. Chapter 16 contributes toward rounding out readers' knowledge regarding certain practical and industrial heat treatment techniques. The 16 chapters of the book are organized for almost linear purview in a graduate-level course, in order to provide concrete understanding through steps. Accordingly, each chapter serves a different purpose, but all chapters are connected to provide an assimilated knowledge of phase transformation through proper correlation between structural evolution and corresponding thermodynamic kinetics.

Designed primarily as an introductory text for undergraduate and postgraduate students of metallurgy, the book also serves the needs of allied scientific disciplines at the undergraduate and graduate levels. With its excellent balance between the fundamentals and advanced information, it can also serve as an invaluable guide for practicing professional engineers and scientists.

The authors are indeed privileged to extend their sincere appreciation and acknowledgment to students, staff, scientists, and faculties of National Institute of Technology, Rourkela, and CSIR-Institute of Minerals and Materials Technology, Bhubaneswar, for their insightful suggestions incorporated into this scholarly manuscript. We shall remain grateful to all around us here for their contributions to meet the need of present students and scholars.

All family members of all authors are truly indebted in our hearts for their unconditional soulful support. 


\section{Authors}

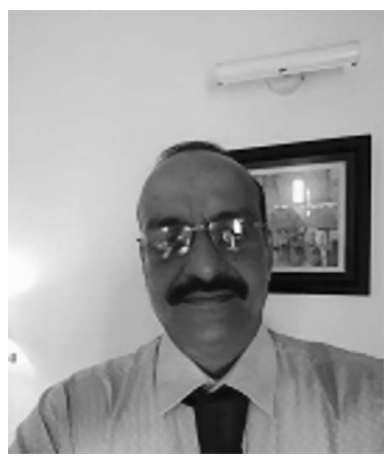

Bankim Chandra Ray, Phd, has worked at the National Institute of Technology (NIT), Rourkela, India, since 1989. A dedicated academician with more than three decades of experience, Bankim Chandra Ray is a full professor since 2006 at the NIT, Rourkela. He earned his $\mathrm{PhD}$ from the Indian Institute of Technology, Kharagpur, India, in 1993. Apart from instructing students in the field of Phase Transformation and Heat Treatment, he has also guided many master's degree and $\mathrm{PhD}$ scholars. He has made seminal contributions in the field of Phase Transformation and Heat Treatment and Composite Materials.

An adept administrator, he has also served as the Dean of Faculty, Head of the Department of the Metallurgical and Materials Engineering, and also an incumbent Coordinator of Steel Research Center at the NIT, Rourkela.

His research interests are mainly focused on the mechanical behavior of FRP composites. He is leading the Composite Materials Group at the NIT, Rourkela, a group dedicated to realizing the technical tangibility of FRP composites (https://www.frpclabnitrkl.com). With numerous highly cited publications in prominent international journals, he has contributed extensively to the world literature in the field of material science and engineering. He also holds a patent deriving from his research. With nearly 155 publications in international journals, Prof. Ray also authored many books/book chapters from leading publishers. He has been associated with several prestigious societies such as Indian Institute of Metals, Indian National Academy of Engineering, and several government and private institutes and organizations. As an advisor to New Materials Business, Tata Steel Ltd., he has been instrumental in facilitating the steel magnate's foray into the FRP composites business. His constant endeavors toward academics and his field of specialization have been unparalleled, and yet thoroughly inspiring for many of the young engineering minds.

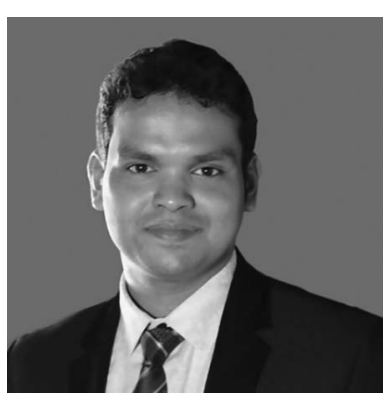

Rajesh Kumar Prusty, PhD, is an enthusiastic and focused teacher who is committed to safeguarding and promoting the education and well-being of students and young people at all times in a friendly and conducive atmosphere. Presently he is an assistant professor at the Department of Metallurgical and Materials Engineering, NIT, Rourkela, India, from 2014. He has graduated with a master's degree (ME) in Materials Engineering from Indian Institute of Science, Bangalore, and earned a PhD from the NIT, Rourkela. $\mathrm{He}$ is fascinated in opening up new dimensions of 
research particularly in the domain of structural materials with the ambition of making these materials very reliable in the Indian market. He has authored more than 25 SCI/Scopus journal articles and one book related to FRP composite materials, and at present, he is a principal investigator of three ongoing projects sponsored by the DRDO, CSIR, and SERB. He actively contributes to the FRP composite lab at the NIT, Rourkela (https://www.frpclabnitrkl.com/) in terms of visualizing and identifying real-time problems associated with FRP composites followed by conceptualizing and designing experiments and work plan accordingly to address those issues through constructive and logical techniques. He has supervised 16 master's and 16 bachelor's theses up to the present. Currently, he has five doctoral and five master's scholars working on FRP composites.

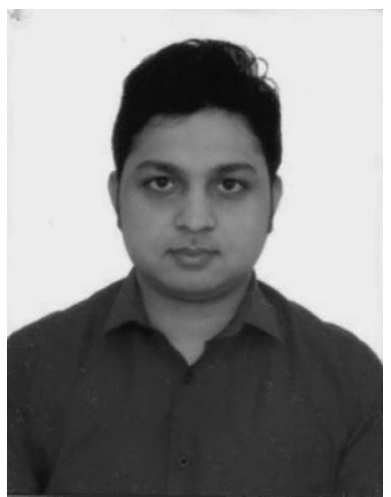

Deepak Nayak is a scientist at the CSIR-Institute of Minerals and Materials Technology, Bhubaneswar, since 2015. Born in 1989 in Bhubaneswar, he graduated from the NIT, Rourkela, with a BTech in Metallurgical and Materials Engineering before working as a graduate engineer trainee at JSL Stainless Ltd., New Delhi, in 2010. Afterward, he returned to Bhubaneswar, where he earned his MTech from Academy of Scientific \& Innovative Research (CSIR-IMMT) in 2013. He manages projects from concept to commercialization in the areas of ferrous metallurgy, including mineral beneficiation of low-grade iron ores, microwave processing, and extraction of valuable metals. 


\section{An Introduction to Metals}

\subsection{ELEMENTS, ATOMS, AND ISOTOPES}

Chemical elements are the fundamental matters of all the materials. These elements are chemically distinct and exhibit unique physical and mechanical properties. The basic representative block of any element is again the atoms, which is comprised of electrons (negatively charged), protons (positively charged), and neutrons (neutral). Both proton and neutron are of almost similar weight, which is around $1.67 \times 10^{-27} \mathrm{~kg}$, whereas electron is much lighter in weight around $9.11 \times 10^{-31} \mathrm{~kg}$. The weight of an atom is almost the same as that of the nucleus, which contains the neutrons and protons. However, the diameter of an atom $\left(\sim 10^{-10} \mathrm{~m}\right.$ or $\left.1 \AA\right)$ is quite larger than that of the nucleus $\left(\sim 10^{-14} \mathrm{~m}\right)$. The magnitude of charge of an electron and a proton being equal, the atom contains exactly the same number of both the entities in order to maintain electrical neutrality. The atomic number of an element indicates the number of protons it possesses in a single atom which is also the same as the number of electrons. However, the difference between atomic weight and atomic number usually indicates the average number of neutrons in the atom. The periodic table designed by the Russian scientist Mendeleev is the ideal tool to find out these numbers for any specific element. Almost all the empty cells in the original Mendeleev's periodic table have been filled due to discovery of new elements in subsequent time. Some elements may have a higher or lower number of neutrons than that of the electrons/protons. As these elements have the same number of electrons/protons, the atomic number is not changed. However, due to different neutrons, the atomic weight becomes different. These are called isotopes. The most common example of isotopes is hydrogen. A high fraction of hydrogen atoms comprises only one proton without any neutron, thus having an atomic weight of 1 . A small fraction of hydrogen atoms contains one proton and one neutron giving rise to an atomic weight of 2 , which are most commonly known as deuterium. Another small fraction of hydrogen atoms known as tritium (atomic weight 3 ) possess one proton and two neutrons. In all these cases, the number of protons is 1 , and all these elements have the same atomic number, but with different atomic weight. Most of the elements in nature are mixture of such multiple isotopes, and thus, the atomic mass is not always a whole number and is the weighted average of the atomic weights of these isotopes. Continuing with the example of hydrogen, in commonly available hydrogen, the isotopes are mixed in such a proportion that the average atomic weight is 1.008. Taking the examples of iron (Fe), it is naturally available in the form of four stable isotopes. The most abundantly available form of iron is ${ }^{56} \mathrm{Fe}(\sim 91.754 \%)$ followed by ${ }^{54} \mathrm{Fe}(\sim 5.845 \%),{ }^{57} \mathrm{Fe}$ $(2.119 \%)$, and ${ }^{58} \mathrm{Fe}(0.282 \%)$, giving rise to an average atomic mass of 55.85 . 


\subsubsection{Types of Elements}

Based on the broad physical and mechanical properties of elements, they are categorized into three groups, i.e., (i) metals, (ii) metalloids, and (iii) nonmetals. Typically, metals are of shiny lustrous appearance, when prepared fresh or fractured. They are good conductors of heat and electricity. Metals can be plastically deformed and are normally malleable (can be made to thin sheets) and ductile (can be drawn into wires). Except mercury, all other metals remain in their solid state at normal room temperature and exhibit crystalline arrangement of atoms. Around 91 out of 118 elements in the periodic table are metal. However, the exact number is not available, as the boundaries between metals, nonmetals, and metalloids fluctuate due to lack of globally accepted basis of categorization. Metals constitute around 25\% of the earth's crust and are inseparable from the present era of civilization. To a large extent, the development of civilization is driven by development in the field of metals and associated products. In the same line, a nonmetal is defined as an element that lacks in the metallic properties. Low density, boiling temperature, and melting temperature are some key physical properties of nonmetals. Most of the nonmetals are gases at room temperature and usually poor conductors of heat and electricity. Some nonmetals are brittle solids at room temperature but good conductors of electricity and heat, e.g., carbon. Metalloids exhibit properties that are in between metals and nonmetals or a mixture of metals and nonmetals. Boron, silicon, germanium, arsenic, antimony, and tellurium are the well-accepted metalloids. They usually have metal-like lustrous appearance but are only moderate conductors of heat and electricity.

\subsection{TYPES OF BONDING BETWEEN ATOMS}

In general, materials in their solid state exhibit a well-arranged array of atoms forming a regular geometric pattern to reduce their free energy. However, solids such as glass, wax, and paraffin do not follow this trend, and the arrangement of atoms is similar to that of the liquid state and thus termed as amorphous solids. The next important point now is to consider the types of forces responsible to have bonds between adjacent atoms in order to complete the structure of the solid. Generally, there exist four types of interatomic bonding.

\subsubsection{IONIC Bond}

Ionic bonding is preferable for elements having large difference in electron negativity. All the elements tend to become stable upon achieving octet configuration, i.e., exactly eight electrons on the outermost shell. However, many of the pure elements do not satisfy this criterion. For example, sodium (atomic number 11) is having only one electron in its outermost shell. Hence, the easiest way for sodium to achieve octet configuration is to donate this single electron. However, as the process does not involve transfer of protons, upon donating the single electron, it becomes positively charged and is termed as a positive ion or cation. For sodium, it is denoted as $\mathrm{Na}^{+}$. All the elements in group IA of the periodic table in this way tend to be single positive cations due to their single valency (e.g., $\mathrm{Na}^{+}, \mathrm{K}^{+}, \mathrm{Cs}^{+}$). 
In a similar way, group IIA elements become double positively charged upon donating two electrons to acquire their respective octet configuration (e.g., $\mathrm{Mg}^{2+}$, $\left.\mathrm{Ca}^{2+}, \mathrm{Ba}^{2+}\right)$. On the contrary, the number of electrons in nonmetals generally is close to eight. Hence, the easiest way for them to achieve the stable octet configuration is to accept the required number of electrons (eight - number of electrons in outermost shell) from somewhere else to have exactly eight electrons at the outermost shell. Considering the case of chlorine, which is having seven electrons in its outermost shell, a single electron is required to be stable. If it gets that electron from somewhere, it becomes single negatively charged (as there is one more electron than the number of protons). This negatively charged ion is termed as anion and denoted as $\mathrm{Cl}^{-}$. Elements corresponding to group VIIA thus tend to be single negatively charged (e.g., $\mathrm{F}^{-}, \mathrm{Cl}^{-}, \mathrm{Br}^{-}$). Similarly, elements in group VIA require two electrons to achieve octet configuration and thus become doubly charged anions (e.g., $\mathrm{O}^{2-}, \mathrm{S}^{2-}$ ). Now, this process of obtaining octet configuration is possible only when there is mutual exchange of electrons, such that electrical neutrality is maintained. For example, the electron donated by $\mathrm{Na}$ is accepted by the nearby $\mathrm{Cl}$ atom in order to neutralize the charge and form a compound named sodium chloride $(\mathrm{NaCl})$ or normal table salt (Figure 1.1). One point here is to note that the properties of the ionic compound formed have nothing to do with the properties of the individual elements, i.e., sodium and chloride. Looking at $\mathrm{NaCl}$, sodium is known as a very reactive element and chlorine is a poisonous gas, but the table salt has neither of these properties, and almost everyone uses this every day without any bad effect. This indicates that ionic bond is a very strong bond. In case of oppositely charged ions with different charge magnitude, a stoichiometry is maintained so as to establish electrical neutrality. For example, one $\mathrm{Mg}^{2+}$ ion is bonded to either one $\mathrm{O}^{2-}$ ion or two $\mathrm{Cl}^{-}$ions forming $\mathrm{MgO}$ and $\mathrm{MgCl}_{2}$, respectively.

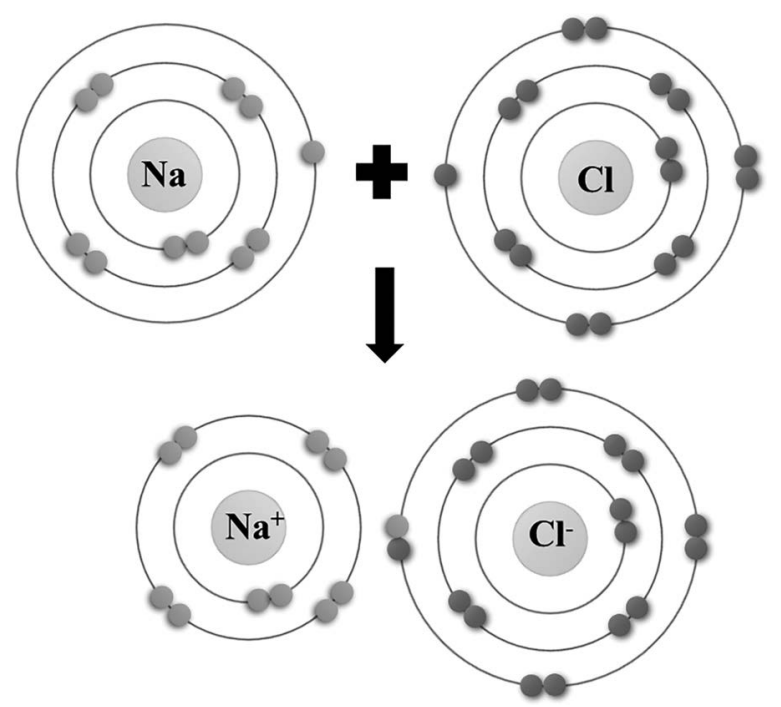

FIGURE 1.1 Formation of $\mathrm{NaCl}$ by ionic bonding between $\mathrm{Na}^{+}$and $\mathrm{Cl}^{-}$. 


\subsubsection{Covalent Bond}

In contrast to ionic bonding, in a covalent bonding, some common electrons are basically shared among two atoms. This bond is mostly formed between atoms of the same element or atoms of the elements that are closely placed in the periodic table. To be more specific, this type of bonding is usually feasible for nonmetals and between metals and nonmetals. Electronegativity of both the atoms being almost the same, neither of them are expected to donate electron(s), and at the same time, these elements normally exhibit high ionization energy. Hence, the best possible way for them is to share some of their outermost shell electrons with each other in order to obtain the stable octet configuration. Carbon is one of the most suited elements for covalent bond, as it is having four electrons in its outer shell. Donating or accepting four electrons to achieve the octet configuration is highly energetically unfavorable. Hence, the carbon atom shares its four electrons with four other electrons by making covalent bonds to achieve stability. For example, hydrogen is having only a single electron in its outer shell and thus requires another electron to achieve stable gas configuration. In order to satisfy this, the four outermost electrons of a single carbon atom form covalent bonds with four such hydrogen atoms as shown in Figure 1.2. By doing so, both carbon and hydrogen obtain the stable gas configuration.

Similarly, another common example of covalent bond is formation of hydrogen gas $\left(\mathrm{H}_{2}\right)$. Each hydrogen atom shares its electron with another atom to achieve stable gas configuration. The strong attraction force or bonding in case of a covalent bond is due to the electrostatic attraction of the shared pair of electrons to the nuclei of both the atoms. For most of the gases, covalent bond is quite preferable.

\subsubsection{Metaluic Bond}

This type of bond is typically prominent in the case of metals in which there is lack both in the availability of oppositely charged ions and in the number of electrons required for covalent bond. Usually, metals are having a tendency to throw their electrons from valence band to the conduction band owing to their high electrical conductivity. This leads to formation of a negatively charged electron cloud around

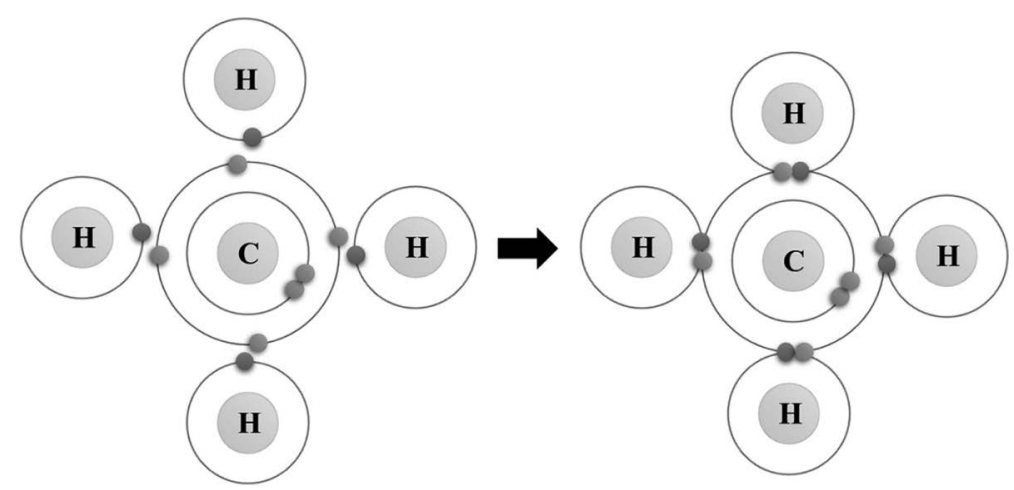

FIGURE 1.2 Formation of methane by covalent bonds between carbon and hydrogen atoms. 

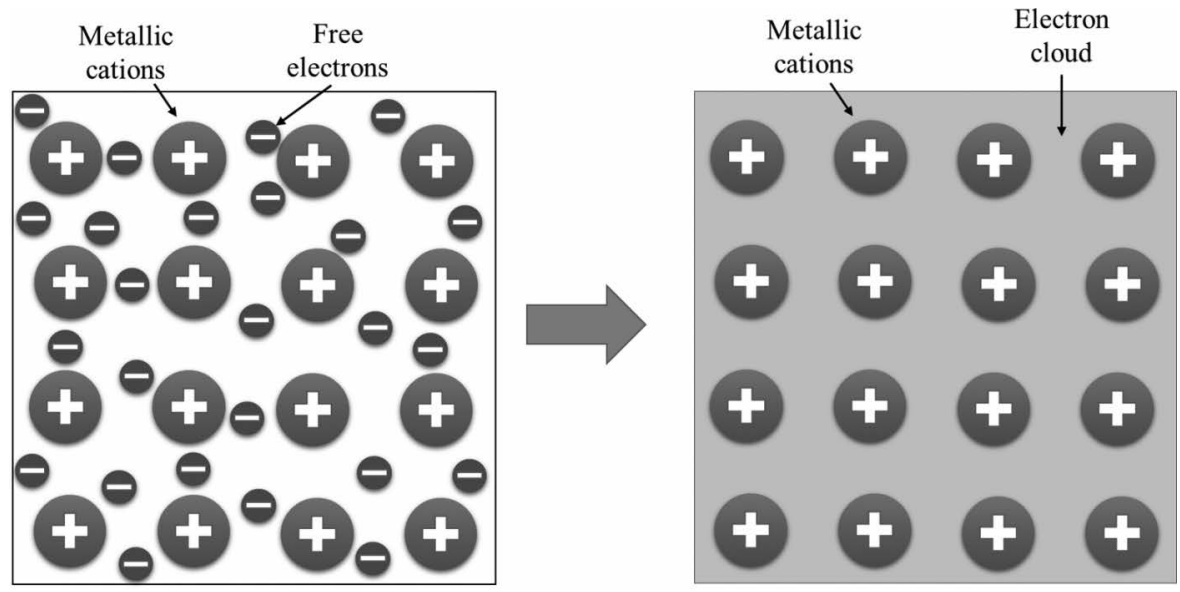

FIGURE 1.3 Illustration of metallic bonding.

the atom. Metallic bond in this case is thus defined as the electrostatic attraction between the positively charged nucleus and the negatively charged electron cloud. In other words, it can also be stated as the sharing of the conduction electrons in a positively charged cation's structure. The metallic atoms thus are bonded together due to their attraction toward the shared sea/cloud/swarm of free electrons around them as shown in Figure 1.3. As this is a kind of sharing of free electrons among the atoms as explained in covalent bonding, metallic bond very often can be considered as extended covalent bond.

Many of the physical and mechanical properties of metals, such as density, strength, ductility, and electrical and thermal conductivity, are due to this metallic bonding among the atoms.

\subsubsection{Van der WaAls Forces}

van der Waals forces are not of the nature of chemical bonds and usually distance dependent. Unlike other atomic bonds explained earlier, these bonds are relatively weak forces and gradually diminished with increasing distance between participating atoms/molecules. If no other force is present among neighboring atoms, then there exists a critical distance between them after which their nuclei start repelling each other due to similar nature of charge. Very often, van der Waals forces are also termed as intermolecular forces. Dipole-dipole forces, dispersion forces, and hydrogen bonding are different types of van der Waals forces. van der Waals forces are operative at lower temperatures where thermal agitation of atoms is minimum.

\subsection{CRYSTAL STRUCTURES}

In a crystalline material, atoms occupy some specific points in the space. An example of atomic arrangement is shown in Figure 1.4a. Atomic positions (center of the atom) can be thought of the points of intersection of an array of infinite length lines. 


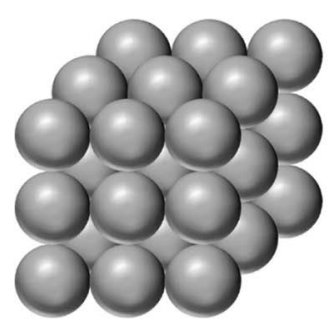

(a)

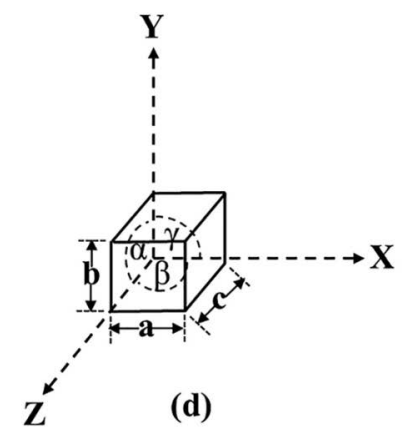

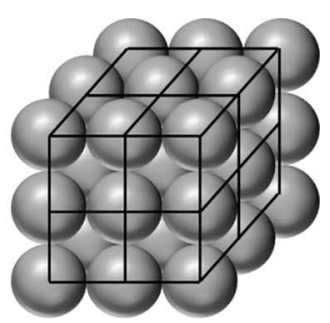

(b)

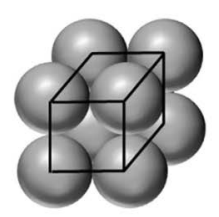

(c)

FIGURE 1.4 Crystalline arrangement: (a) an array of atoms in space, (b) construction of space lattice (a network of lines), (c) a representative volume element (unit cell), and (d) parameters of a unit cell.

This array of straight lines is termed as space lattice (Figure 1.4b). These atomic positions are identical to each other, or in other words, all the atoms are having the same surroundings. A basis or motif can be defined as a group of atoms that are located at a particular order with respect to each other. Combination of both the lattice and motif gives rise to the complete crystal structure of the atoms. A unit cell in a crystal is further defined as the smallest representative volume element (Figure 1.4c), which upon repetition in all three dimensions yields the complete crystal structure. A unit cell is a fundamental entity of all the crystalline materials. A unit cell is constituted by its six parameters, three intersecting axial lengths (sides), and correspondingly three angles between each pair of axes. The unit cell dimensions in the $X, Y$, and $Z$ (not necessarily perpendicular to each other) directions are normally represented by $a, b$, and $c$, respectively. $\alpha, \beta$, and $\gamma$ represent the angles between $Y$ and $Z, Z$ and $X$, and $X$ and $Y$, respectively, as shown in Figure 1.4d.

All the possible space lattices can be formed from seven different crystal systems or unit cells. These seven crystal systems are different from each other based on the values of $a, b, c, \alpha, \beta$, and $\gamma$. These possible crystal systems are reported in Table 1.1 .

Interestingly, most of the important metals crystallize in two particular crystal systems, i.e., cubic and hexagonal, and only three Bravais lattices are common such as face-centered cubic (FCC), body-centered cubic (BCC), and close-packed hexagonal $(\mathrm{CPH})$. 
TABLE 1.1

Various Possible Crystal Systems and Corresponding Bravais Lattices

Crystal

System

Sides Angles

Triclinic

$a \neq b \neq c \quad \alpha \neq \beta \neq \gamma \neq 90^{\circ}$

Monoclinic

$a \neq b \neq c \quad \alpha=\gamma=90^{\circ} \neq \beta$

Possible Bravais Lattices

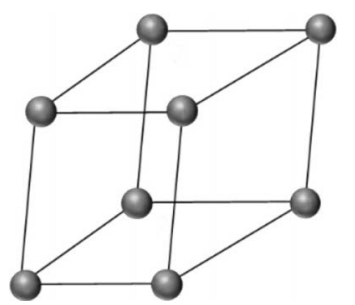

Simple triclinic

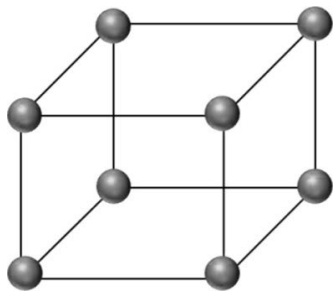

Simple monoclinic

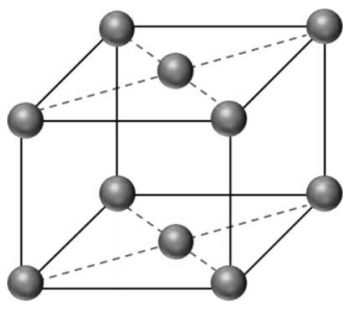

Base-centered monoclinic

Hexagonal

$a=b \neq c \quad \alpha=\beta=90^{\circ}, \gamma=120^{\circ}$

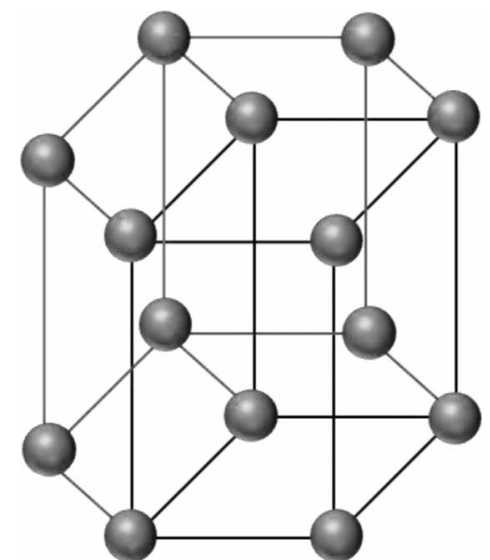

Simple hexagonal

(Continued) 
TABLE 1.1 (Continued)

Various Possible Crystal Systems and Corresponding Bravais Lattices

Crystal

System

Sides

Angles

Possible Bravais Lattices

Rhombohedral/

$a=b=c$

$\alpha=\beta=\gamma \neq 90^{\circ}$

trigonal

Orthorhombic $\quad a \neq b \neq c \quad \alpha=\beta=\gamma=90^{\circ}$

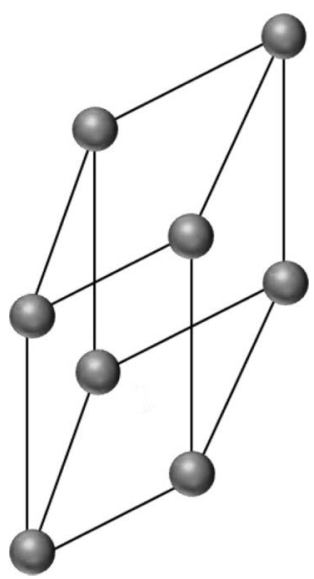

Simple trigonal

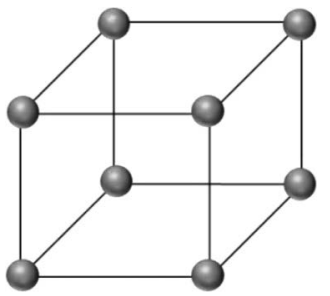

Simple orthorhombic

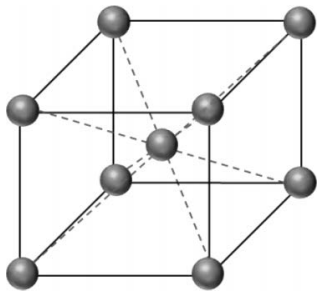

Body-centered orthorhombic

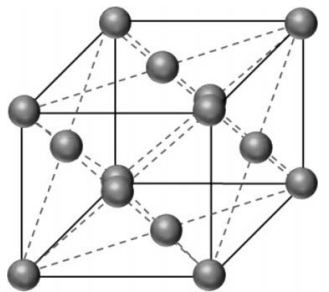

Face-centered orthorhombic 
TABLE 1.1 (Continued)

Various Possible Crystal Systems and Corresponding Bravais Lattices

Crystal

System

Sides

Angles

Possible Bravais Lattices

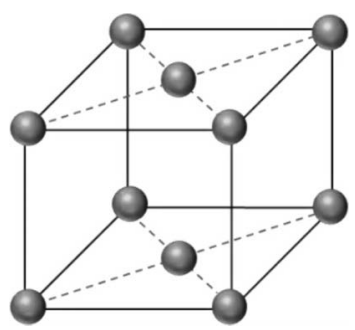

Base-centered orthorhombic

Tetragonal

$a=b \neq c \quad \alpha=\beta=\gamma=90^{\circ}$

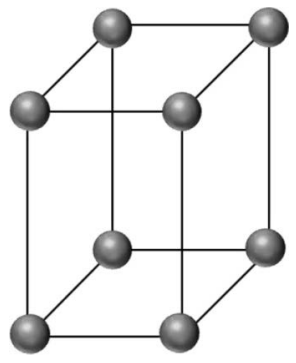

Simple tetragonal

Cubic

$$
a=b=c \quad \alpha=\beta=\gamma=90^{\circ}
$$

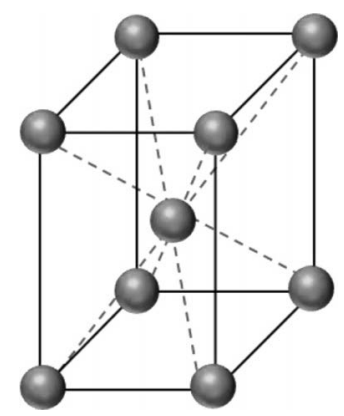

Body-centered tetragonal

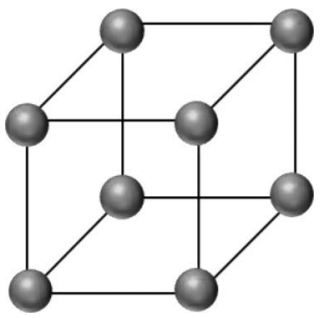

Simple cubic 
TABLE 1.1 (Continued)

Various Possible Crystal Systems and Corresponding Bravais Lattices

Crystal

System

Sides

Angles

Possible Bravais Lattices

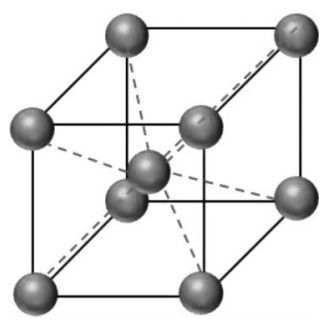

Body-centered cubic

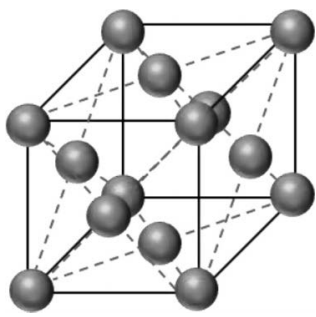

Face-centered cubic

\subsubsection{Face-Centered Cubic Structure}

In this structure, the unit cell is cubic in nature $\left(a=b=c\right.$ and $\left.\alpha=\beta=\gamma=90^{\circ}\right)$, and the atoms occupy the cube corners and face centers as shown in Table 1.1. An infinite array of atoms with FCC arrangement is shown in Figure 1.5a. The smallest repeating unit of this can thus be extracted as shown in Figure 1.5b. Consider the righthand-side face of the cube in Figure 1.5b. This face is common to two unit cells, one shown in the figure and the other just immediate next right to it.

As can be seen, the corner atoms are not touching each other. The face center atom of this right-side face (shown as atom " $\mathrm{X}$ ") touches the four corner atoms on that particular face, four face center atoms (top, bottom, front, and back) of the shown unit cell, and similarly four face center atoms of the adjacent right unit cell. Thus, an atom is having 12 nearest neighboring atoms, and therefore, the coordination number of an FCC atom is 12. A representative of the atomic location in the unit cell is shown in Figure 1.5c. However, note that in this figure the spheres (corner and face center) represent the center of the atom (readers should not assume the size of this sphere to be the same as that of the corresponding atom; it is just for the sake of simple representation).

Many of the ductile metals such as copper, aluminum, nickel, silver, and $\gamma$-iron crystallize in the FCC form. 


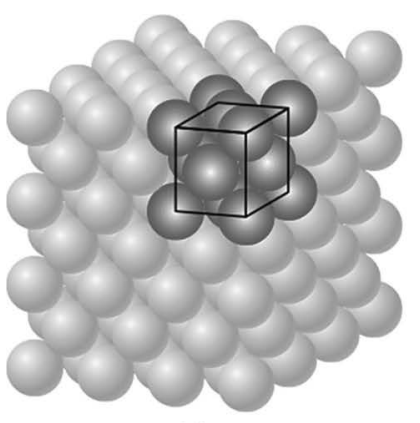

(a)

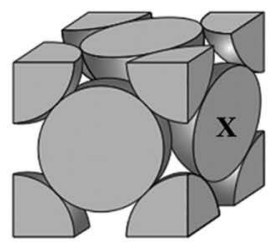

(b)

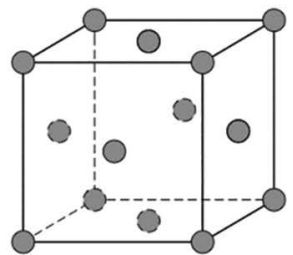

(c)

FIGURE 1.5 Face-centered cubic structure: (a) arrangement of atoms, (b) atomic position in a single unit cell, and (c) representative unit cell with atomic locations.

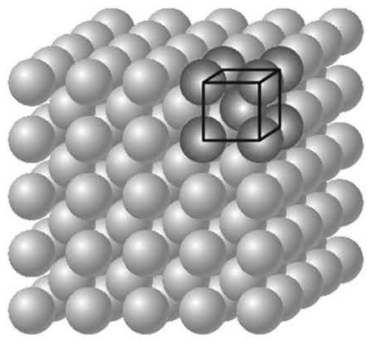

(a)

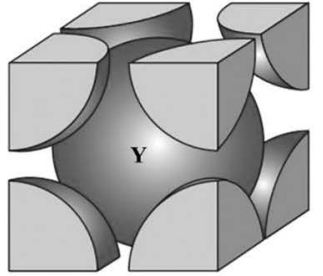

(b)

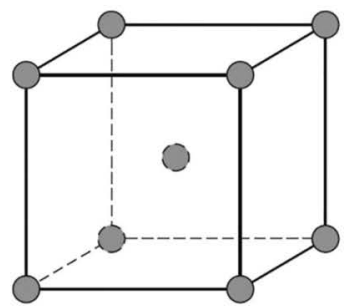

(c)

FIGURE 1.6 Body-centered cubic structure: (a) arrangement of atoms, (b) atomic position in a single unit cell, and (c) representative unit cell with atomic locations.

\subsubsection{Body-Centered Cubic Structure}

In a similar way, a BCC crystal exhibits a cubic unit cell with atoms located at all the cube corners and at the body center. The corner atoms do not touch each other. However, the body-centered atom (shown as atom "Y") touches all the eight corner atoms of the unit cell. Thus, the number of nearest neighbors or coordination number of a BCC atom is eight. The array of atoms, atomic arrangement in a unit cell, and a representative unit cell have been represented in Figure 1.6a, b, and c, respectively.

Metals such as vanadium, sodium, tungsten, barium, and $\alpha$-iron crystallize in the BCC form.

\subsubsection{Close-Packed Hexagonal}

A CPH or hexagonal close-packed (HCP) structure usually comprises two parallel planes containing 2-D hexagonal lattices with atoms placed at the corners and center of the hexagons (Figure 1.7a). These closely packed planes are known as basal planes (or A plane). In addition, on the horizontal plane (or B plane), which is located 


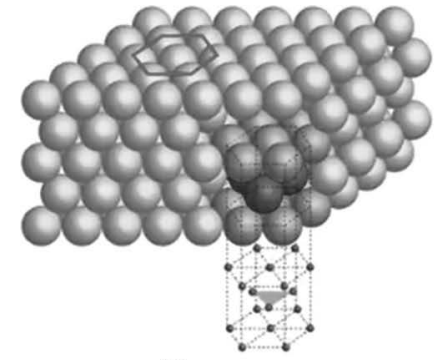

(a)

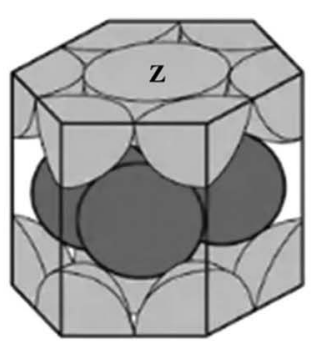

(b)

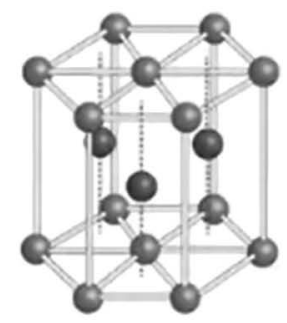

(c)

FIGURE 1.7 Close-packed hexagonal structure: (a) arrangement of atoms, (b) atomic position in a single unit cell, and (c) representative unit cell with atomic locations.

exactly at the vertical center of these two basal planes, three more atoms are present in the form of a triangle as shown in Figure 1.7c. The basal plane can be divided into six identical equilateral triangles, and the projections of the centers of the three atoms of the middle plane coincide with the centroid of the alternate equilateral triangles on the basal plane. As one can visualize, the central atom of a hexagonal lattice on the basal plane (top face of the hexagonal lattice shown in Figure 1.7b, shown as atom "Z") makes bond with each of the six hexagonal corner atoms. In addition, it also forms bonds with each three atoms of the B plane enclosed in the unit cell. In a similar way, there also exists another B plane above the top face of the hexagon corresponding to the next unit cell. Three atoms of this B plane form bonds with atom " $Z$." Thus, the coordination number of a CPH atom is 12 . The vertical line joining the face-centered atoms of the top and bottom surface passes through the centroid of the equilateral triangle formed by the three atoms in the middle plane. Metals such as cadmium, cobalt, zinc, magnesium, and $\alpha$-titanium crystallize in the $\mathrm{CPH}$ structure.

If one closely observes the atomic arrangements of FCC and $\mathrm{CPH}$, there is a very little difference. Figure 1.8 is provided to figure out the structural difference in arrangement of atoms in FCC and CPH. Let us first consider a layer of closely packed atoms as shown in Figure 1.8a. This is the most closely packed configuration of atoms, or atomic plane with least possible free space. In this arrangement, each atom is touching and surrounded by six atoms. Let this position be called as A plane, i.e., the centers of all the atoms are placed in "A" position as shown in Figure 1.8b. Now, there are two types of void location in this plane, i.e., "B" and "C." That means for close packing in the $z$-direction, the centers of the atoms of the next layer must be placed either vertically above "B" or above "C." Let us assume the next layer to be of "B" type as shown in Figure 1.8c. After this, the next or third layer will decide whether it will be of FCC or $\mathrm{CPH}$ structure. After placement of the second atomic layer at "B" position, the centers of the atoms of the third layer may be placed either vertically above "A" or above "C." If it is placed at "A" position, it is termed as "ABCABC..." stacking or FCC configuration as shown in Figure 1.8d. On the contrary, if the third layer of atoms are placed at "A" position, it is termed as "ABAB..." stacking, and consequently, the arrangement is known as $\mathrm{CPH}$ packing as shown in Figure 1.8e. 


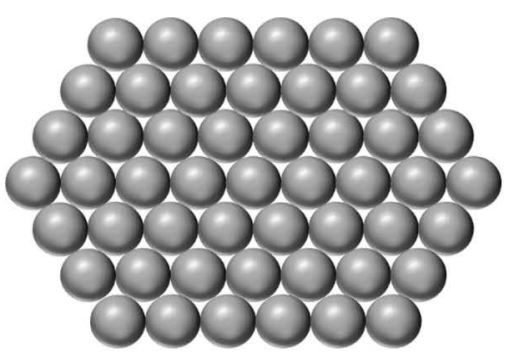

(a)

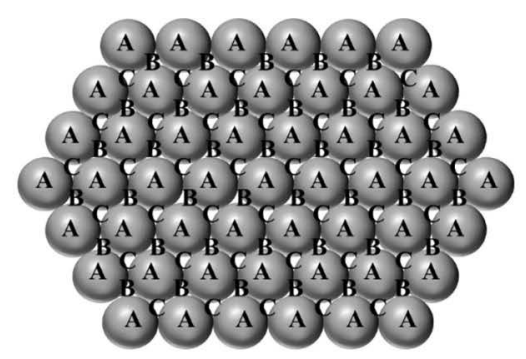

(b)

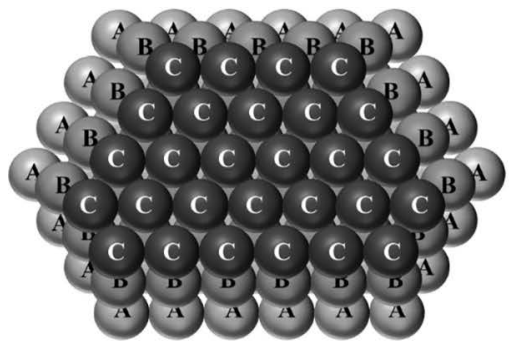

(d)

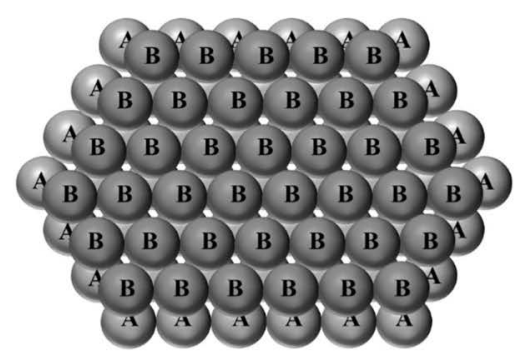

(c)

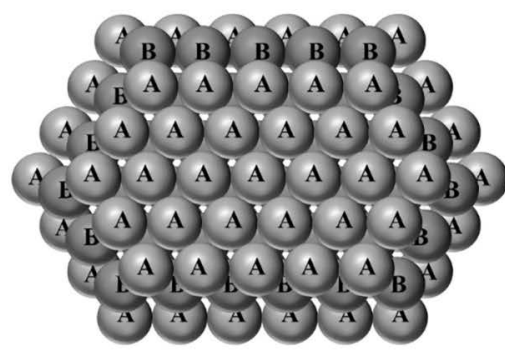

(e)

FIGURE 1.8 Layer-by-layer arrangement of atomic planes in the case of FCC and CPH. FCC, face-centered cubic; $\mathrm{CPH}$, close-packed hexagonal.

Hence, the stacking sequence of atomic planes or the position of the atomic centers of the atomic planes makes FCC different from CPH. However, it is very evident from the previous explanation that the atomic packing is the same for both the structures.

\subsubsection{Allotropy}

The term "Allotropes" comes from the Greek, where "allos" means another and "tropes" means manner or style. Hence, allotropes means that an element may crystallize in different crystal structure in its solid form. The best example of allotropes is iron. When a liquid iron is cooled down at normal atmospheric pressure, it solidifies at $1539^{\circ} \mathrm{C}$, has $\mathrm{BCC}$ crystal structure, and is known as $\delta$-iron. Upon further cooling, this $\delta$-iron converts to $\gamma$-iron at $1394^{\circ} \mathrm{C}$. $\gamma$-Iron has FCC crystal structure and is stable up to $912^{\circ} \mathrm{C}$ after which it again converts to a BCC structure known as $\alpha$-iron. $\beta$-Iron also exists but mostly becomes obsolete these days having the same crystal structure 
as $\alpha$-iron, but having paramagnetic behavior. Upon heating the ferromagnetic $\alpha$-iron, it loses its magnetism above the Curie temperature, which is $770^{\circ} \mathrm{C}$, and becomes paramagnetic $\beta$-iron. However, the crystal structures of both $\alpha$-iron and $\beta$-iron are identical. Another well-known element for allotropes is carbon. Carbon crystallizes with several allotropic forms, i.e., diamond having tetrahedral structure, graphite having hexagonal structure, and fullerenes including Bucky balls $\left(\mathrm{C}_{60}\right)$. Other metals such as tin, cobalt, and polonium also exhibit allotropes.

\subsubsection{Packing Factor/Efficiency}

Packing factor or packing fraction (PF) or packing efficiency of a crystal structure is defined as the ratio of the volume of atoms enclosed in a unit cell to the total volume of the unit cell. This is basically an entity to estimate the extent of packing or, in other words, the extent of available free space in the crystal structure. Let us thus find out the PF of the aforementioned three most common crystal structures.

As per the definition of PF, it can be mathematically represented as

$$
\mathrm{PF}=\frac{\text { Total volume of the atoms enclosed in an unit cell }}{\text { Total volume of the unit cell }}
$$

The next term now comes is the effective number of atoms. Very often, an atom in a unit cell does not completely belong to that particular atom; rather, it is shared among some adjoining unit cells. For example, a face-centered atom is shared among two unit cells. From this, the PF can be further simplified as

$$
\mathrm{PF}=\frac{\text { No. of effective atoms } \times \text { volume of a single atom }}{\text { Total volume of the unit cell }}
$$

The number of effective atoms is basically the total number of atoms that solely correspond to only a single unit cell. This can be further mathematically defined as

$$
\text { No. of effective atoms }=\sum_{i} C_{i} n_{i}
$$

$C_{i}=$ contribution of the $i$ th type of atoms to the unit cell, and

$n_{i}=$ the total number of $i$ th type of atoms in the unit cell.

In this way, let us find out the PF of the crystal structures.

\subsubsection{Packing Fraction of a Body-Centered Cubic Structure}

Let us consider a BCC single unit cell ABCDEFGH as discussed earlier and shown in Figure 1.9a. Here, there are two types of atoms: (i) cube corner atoms and (ii) body center atoms.

A cube corner is basically common to eight adjacent cubes. Hence, the atom at the cube corner is shared by the same eight unit cells. As a consequence, $\frac{1}{8}$ th volume of the atom is enclosed by a single unit cell. Thus, $C_{C}=\frac{1}{8}$ for the cube corner atom 


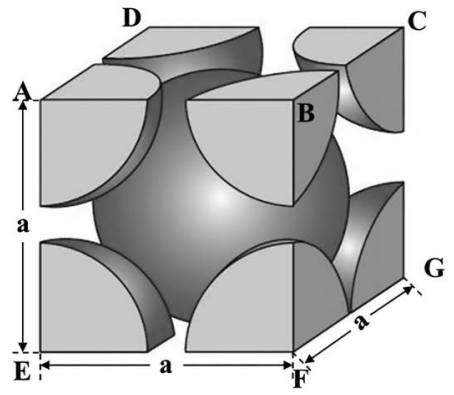

(a)

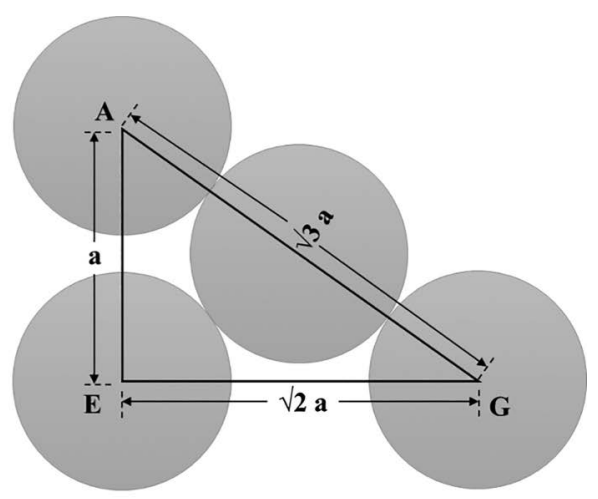

(b)

FIGURE 1.9 Atomic arrangement of BCC crystal structure. BCC, body-centered cubic.

in this BCC structure, and there are eight such cube corners making $n_{C}=8$. Then, consider the body center atom. The entire body center atom is enclosed in a single unit cell. Thus, $C_{B C}=1$, and there is only one such body center atom in a unit cell $\left(n_{B C}=1\right)$.

$$
\text { No. of effective atoms }=\sum_{i} C_{i} n_{i}=C_{C} \times n_{C}+C_{B C} \times n_{B C}=\frac{1}{8} \times 8+1 \times 1=2
$$

Assuming atoms to be of spherical shape and taking the atomic radius to be $r$ and lattice parameter to be $a$,

$$
\mathrm{PF}=\frac{\text { No. of effective atoms } \times \text { volume of a single atom }}{\text { Total volume of the unit cell }}=\frac{2 \times \frac{4}{3} \pi r^{3}}{a^{3}}
$$

Now, we require a relation between $r$ and $a$ in order to find out the exact PF for the structure. For this, consider the right angle triangle AEG as shown in Figure 1.9b. EG corresponds to the face diagonal of the side EFGH having square shape. Thus, the length of EG becomes " $\sqrt{ } 2 a$ " (Pythagorean theorem) as shown in the figure. The size and location of the atoms are also clearly visible in the figure (i.e., the body center atom touches all other atoms). Thus, the diagonal AG of the right angle triangle AEG is " $\sqrt{ } 3 a$." From the figure, it can also be seen that $A G$ is four times the radius of the atom, i.e., $\mathrm{AG}=4 r$. Hence,

$$
\begin{aligned}
& \sqrt{3} a=4 r \\
& \text { Hence, } \mathrm{PF}=\frac{2 \times \frac{4}{3} \pi r^{3}}{a^{3}}=\frac{\frac{8}{3} \pi r^{3}}{\left(\frac{4}{\sqrt{3}} r\right)^{3}}=\frac{\frac{8}{3} \pi}{\frac{64}{3 \sqrt{3}}}=0.68
\end{aligned}
$$

Hence, for a BCC structure, the packing efficiency is 0.68 or $68 \%$. 


\subsubsection{Packing Fraction of a Face-Centered Cubic Structure}

In a similar way, the PF of an FCC crystal structure can also be determined. Consider the unit cell of FCC crystal structure ABCDEFGH as shown in Figure 1.10a. The atoms are located at the cube corners and at the face centers. Each face center atom is shared by two adjacent unit cells having a common face. Hence, $C_{B C}=\frac{1}{2}$, and there are total such face center atoms in each unit cell, i.e., $n_{B C}=6$. As explained in the case of BCC, in the FCC structure also, $C_{C}=\frac{1}{8}$ and $n_{C}=8$. The number of effective
atoms is thus

$$
\text { No. of effective atoms }=\sum_{i} C_{i} n_{i}=C_{C} \times n_{C}+C_{F C} \times n_{F C}=\frac{1}{8} \times 8+\frac{1}{2} \times 6=4
$$

Assuming atoms to be hard spheres, the packing factor now is

$$
\mathrm{PF}=\frac{\text { No. of effective atoms } \times \text { volume of a single atom }}{\text { Total volume of the unit cell }}=\frac{4 \times \frac{4}{3} \pi r^{3}}{a^{3}}
$$

Now, to establish a relation between $a$ and $r$, consider the right angle triangle AEF as shown in Figure 1.10b, where it can be clearly noticed that the face-centered atom is touching all the corner atoms of the face. Hence, the diagonal AF of the right angle triangle $\mathrm{AEF}$ is

$$
\mathrm{AF}=\sqrt{2} a=4 r
$$

Hence,

$$
\mathrm{PF}=\frac{4 \times \frac{4}{3} \pi r^{3}}{a^{3}}=\frac{4 \times \frac{4}{3} \pi r^{3}}{(2 \sqrt{ } 2 r)^{3}}=0.74
$$

Therefore, FCC is a denser structure than BCC having a PF of 0.74 or $74 \%$.

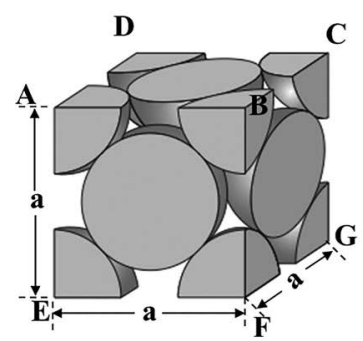

(a)

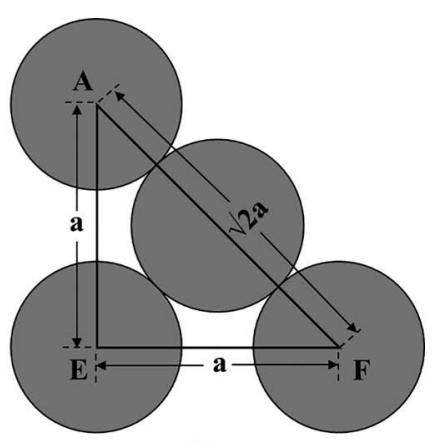

(b)

FIGURE 1.10 Atomic arrangement of FCC crystal structure. FCC, face-centered cubic 


\subsubsection{Packing Fraction of a Close-Packed Hexagonal Structure}

For obtaining the PF of a $\mathrm{CPH}$ structure, one first needs to determine the volume of the unit cell. Unlike a cubic structure, the sides of a hexagonal structure are not equal, i.e., $a=b \neq c$.

If one clearly observes the arrangement of atoms in the $\mathrm{CPH}$ structure, it can be noticed that in a unit cell, there exists a middle horizontal plane containing three atoms, which is exactly midway between the two parallel hexagons (basal planes) as shown in Figure 1.11a. The length of each side of the hexagon and the vertical distance between the hexagons are represented by " $a$ " and "c," respectively. As the basal plane is the most closely packed plane, each atom touches six neighboring atoms. Thus, the side of the hexagon is equal to the diameter of the atoms ( $a=2 r, r$ is the radius of the atom). Furthermore, each of the hexagons of the unit cell can be divided into six equilateral triangle as shown in Figure 1.11b. And the centers of the atoms in the middle plane exist exactly at the middle points of the vertical lines joining the centroids of each pair of the alternate equilateral triangles as shown in Figure 1.11b. A simplified version of this arrangement has been presented in Figure 1.11c. The atom "D" (an atom of the middle plane) sits just vertically above the centroid of the equilateral triangle formed by A, B, and C atoms. However, all these four atoms

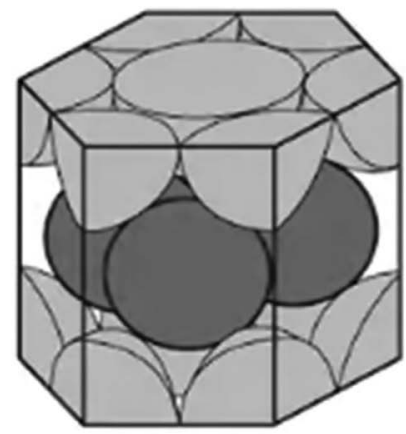

(a)

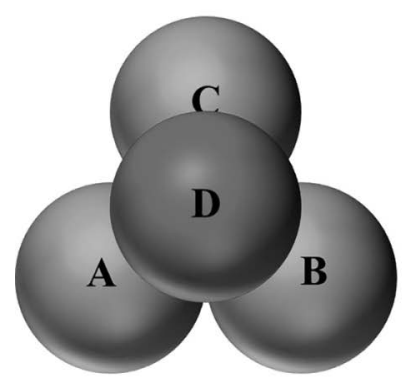

(c)

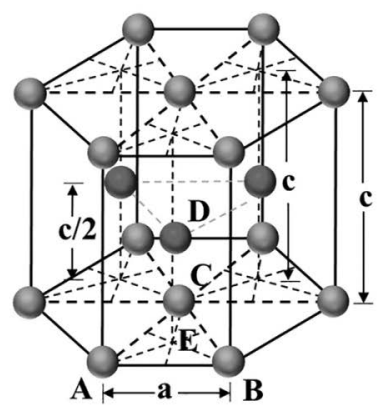

(b)

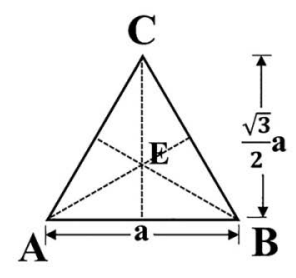

(d)

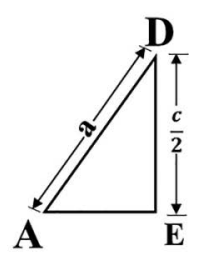

(e)

FIGURE 1.11 Arrangement of atoms in CPH structure and determination of its PF. CPH, close-packed hexagonal; PF, packing fraction. 
(A, B, C, and D) touch each other (discussed earlier). The volume of the hexagonal unit cell can be obtained by multiplying the area of the hexagon with the height. Therefore, a relation must be established between the lattice parameters " $c$ " and " $a$ " in order to represent the volume only in terms of " $a$." For that, consider the equilateral triangle obtained by the centers of atoms A, B, and C as shown in Figure 1.11d. $\mathrm{E}$ is the centroid of this triangle, and hence, the center of atom $\mathrm{D}$ is exactly vertically above the point $\mathrm{E}$. As the distance between the vertex and centroid of the triangle is two-thirds of the length of the median,

$$
\mathrm{AE}=\frac{2}{3} \times \sqrt{a^{2}-\frac{a^{2}}{4}}=\frac{2}{3} \times \frac{\sqrt{3}}{2} a=\frac{a}{\sqrt{3}}
$$

Now, again a right angle triangle can be visualized, which is obtained by the points A, E, and D as shown in Figure 1.11e. As the atom D touches all the atoms A, B, and $\mathrm{C}$, the distance between the centers of atoms $\mathrm{D}$ and $\mathrm{A}$ is equal to the diameter of the atoms, which is again equal to the lattice parameter " $a$." The vertical distance between the centers of the atoms A and D is half of the height of the hexagon, i.e., $\mathrm{DE}=\frac{c}{2}$

$$
\begin{gathered}
\mathrm{As}, \mathrm{DE}=\sqrt{\mathrm{AD}^{2}-\mathrm{AE}^{2}} \\
\frac{c}{2}=\sqrt{a^{2}-\frac{a^{2}}{3}}\left(\mathrm{As} \mathrm{AD}=a \text { and } \mathrm{AE}=\frac{a}{\sqrt{3}}\right) \\
\text { Or, } \frac{c}{2}=\sqrt{\frac{2}{3}} a=0.816 a \\
\text { Or, } c=1.632 a
\end{gathered}
$$

Now, Total volume of the unit cell $=$ area of the hexagon $\times$ height of the unit cell

Total volume of the unit cell $=\frac{3 \sqrt{3}}{2} a^{2} \times c=\frac{3 \sqrt{3}}{2} a^{2} \times 1.632 a=4.24 a^{3}=33.92 r^{3}$

Each atom at the corner of the hexagon is shared by six such unit cells, and thus, the contribution of a single corner atom to a single unit cell is $\frac{1}{6}$, and there are six such corner atoms in each of the hexagon making a total of 12 corner atoms. The face center atom at the center of each basal hexagonal plane is shared among two such unit cells; thus, its contribution toward the unit cell is $\frac{1}{2}$, and there are two such face center atoms in a single unit cell. All the three atoms in the middle plane belong to only a single unit cell. Thus,

$$
\text { No. of effective atoms }=\frac{1}{6} \times 12+\frac{1}{2} \times 2+1 \times 3=6
$$


Therefore,

$$
\mathrm{PF}=\frac{\text { No. of effective atoms } \times \text { volume of a single atom }}{\text { Total volume of the unit cell }}=\frac{6 \times \frac{4}{3} \pi r^{3}}{33.92 r^{3}}
$$

Thus, $\mathrm{PF}=0.74$ or $74 \%$

From the previous discussion, it is very clear that both FCC and CPH have the same $\mathrm{PF}$, which is also quite expected due to the layer-by-layer stacking of closely packed atomic planes as discussed earlier. However, the BCC structure is less densely packed in comparison to FCC and $\mathrm{CPH}$.

\section{FURTHER READING}

Avner, S. H. Introduction to Physical Metallurgy. (Tata McGraw-Hill Education, New York, 1997).

Azaroff, L. V. Introduction to Solids. (Tata McGraw-Hill Education, New York, 1960).

Porter, D. A. \& Easterling, K. E. Phase Transformations in Metals and Alloys, Third Edition (Revised Reprint). (CRC Press, Boca Raton, FL, 1992).

Dieter, G. E. Mechanical Metallurgy. (McGraw-Hill, New York, 1988).

Abbaschian, R. \& Reed-Hill, R. E. Physical Metallurgy Principles. (Cengage Learning, Massachusetts, 2008).

Hosford, W. F. Physical Metallurgy, Second Edition. (Taylor \& Francis, Boca Raton, FL, 2010).

Porter, D. A. \& Easterling, K. E. Phase Transformations in Metals and Alloys, Third Edition (Revised Reprint). (CRC Press, Boca Raton, FL, 1992).

Avner, S. H. Introduction to Physical Metallurgy. (Tata McGraw-Hill Education, New York, 1997).

Clark, D. S. \& Varney, W. R. Physical Metallurgy for Engineers. (Litton Educational Publishing Inc., New York, 1962).

Abbaschian, R. \& Reed-Hill, R. E. Physical Metallurgy Principles. (Cengage Learning, Massachusetts, 2008).

Raghavan, V. Physical Metallurgy: Principles and Practice. (PHI Learning Pvt. Ltd., New Delhi, 2006).

Avner, S. H. Introduction to Physical Metallurgy. (Tata McGraw-Hill Education, New York, 1997).

Porter, D. A. \& Easterling, K. E. Phase Transformations in Metals and Alloys, Third Edition (Revised Reprint). (CRC Press, Boca Raton, FL, 1992).

Singh, V. Physical Metallurgy. (Standard Publishers Distributors, New Delhi, 2005).

Avner, S. H. Introduction to Physical Metallurgy. (Tata McGraw-Hill Education, New York, 1997).

Sharma, R. C. Principles of Heat Treatment of Steels. (New Age International, New Delhi, 2003).

Singh, V. Heat Treatment of Metals. (Standard Publishers Distributors, New Delhi, 2006).

Rajan, T. V., Sharma, C. P., \& Sharma, A. Heat Treatment: Principles and Techniques. (PHI Learning Pvt. Ltd., New Delhi, 2011).

Singh, V. Heat Treatment of Metals. (Standard Publishers Distributors, New Delhi, 2006).

Rajan, T. V., Sharma, C. P., \& Sharma, A. Heat Treatment: Principles and Techniques. (PHI Learning Pvt. Ltd., New Delhi, 2011). 
Singh, V. Heat Treatment of Metals. (Standard Publishers Distributors, New Delhi, 2006).

Rajan, T. V., Sharma, C. P., \& Sharma, A. Heat Treatment: Principles and Techniques. (PHI Learning Pvt. Ltd., New Delhi, 2011).

Avala, L. Concepts in Physical Metallurgy. (Morgan \& Claypool Publishers, San Rafael, CA, 2017).

Avner, S. H. Introduction to Physical Metallurgy. (Tata McGraw-Hill Education, New York, 1997).

Singh, V. Heat Treatment of Metals. (Standard Publishers Distributors, New Delhi, 2006).

Rajan, T. V., Sharma, C. P., \& Sharma, A. Heat Treatment: Principles and Techniques. (PHI Learning Pvt. Ltd., New Delhi, 2011).

Avner. Introduction to Physical Metallurgy. (Tata McGraw-Hill Education, New York, 1997).

Rajan, T. V., Sharma, C. P. \& Sharma, A. Heat Treatment: Principles and Techniques. (PHI Learning Pvt. Ltd., New Delhi, 2011).

Singh, V. Heat Treatment of Metals. (Standard Publishers Distributors, New Delhi, 2006).

Rajan, T. V., Sharma, C. P., \& Sharma, A. Heat Treatment: Principles and Techniques. (PHI Learning Pvt. Ltd., New Delhi, 2011).

Sinha, A. K. Defects and distortion in heat-treated parts. ASM Handb. 4, 601-619 (1991).

Singh, V. Heat Treatment of Metals. (Standard Publishers Distributors, New Delhi, 2006).

\section{REFERENCES}

1. Crystal Defects: Linear Defects (Dislocations). https://www.nde-ed.org/ EducationResources/CommunityCollege/Materials/Structure/linear_defects.htm.

1. Sharma, R. C. Phase Transformations in Materials (PB). (CBS Publ., New Delhi, 2002).

2. Zhao, J.-C. \& Notis, M. R. Continuous cooling transformation kinetics versus isothermal transformation kinetics of steels: A phenomenological rationalization of experimental observations. Mater. Sci. Eng. R Rep. 15, 135-207 (1995).

1. Sajjadi-Nikoo, S., Pouranvari, M., Abedi, A., \& Ghaderi, A. A. In situ postweld heat treatment of transformation induced plasticity steel resistance spot welds. Sci. Technol. Weld. Joining 23, 71-78 (2018).

2. Zhang, Z., et al. Effect of post-weld heat treatment on microstructure evolution and pitting corrosion behavior of UNS S31803 duplex stainless steel welds. Corros. Sci. 62, 42-50 (2012).

1. Radzikowska, J. M. Effect of specimen preparation on evaluation of cast iron microstructures. Mater. Charact. 54, 287-304 (2005).

1. Association, A. G. Distortion \& Warping. American Galvanizers Association https:// galvanizeit.org/design-and-fabrication/design-considerations/distortion-and-warping (2020).

2. 7 Causes for Quench Cracking of Steel. Speaking of Precision Blog https://pmpaspeakingofprecision.com/2010/08/03/7-causes-for-quench-cracking-of-steel/ (2010).

3. Vander Voort, G. F. Understanding and Measuring Decarburization. (ASM INT Subscriptions Specialist Customer Service, Materials Park, OH, 2015).

4. Munda, P., Husain, Md. M., Rajinikanth, V., \& Metya, A. K. Evolution of microstructure during short-term overheating failure of a boiler water wall tube made of carbon steel. J. Fail. Anal. Prev. 18, 199-211 (2018).

1. Asnafi, N., Shams, T., Aspenberg, D. \& Öberg, C. 3D metal printing from an industrial perspective-product design, production, and business models. BHM BergHüttenmänn. Monatshefte 164, 91-100 (2019).

2. Driveshaft. Simple English Wikipedia, the free encyclopedia (2014).

3. Wang, Z., Zhang, T., Zhang, Z., Yuan, Y. \& Liu, Y. A high-efficiency regenerative shock absorber considering twin ball screws transmissions for application in range- 
extended electric vehicles. Energy Built Environ. 1, 36-49 (2020).

4. Dual-clutch transmission. Wikipedia. https://en.wikipedia.org/wiki/Dual-clutch_ transmission.

5. Yu, Z. \& Xu, X. Failure analysis of a diesel engine crankshaft. Eng. Fail. Anal. 12, 487-495 (2005).

6. Qin, Z., Zhang, Q., Wu, Y.-T., Eizad, A. \& Lyu, S.-K. Experimentally validated geometry modification simulation for improving noise performance of CVT gearbox for vehicles. Int. J. Precis. Eng. Manuf. 20, 1969-1977 (2019).

7. Funatani, K. Heat treatment of automotive components: current status and future trends. Trans. Indian Inst. Met. 57, 381-396 (2004).

8. Ejection seat. Wikipedia (2019).

9. El-Sayed, A. F. Aircraft propulsion and gas turbine engines. (CRC press, Cleveland, $\mathrm{OH}, 2017)$.

10. Landing gear. Wikipedia (2020).

11. Hermawan, H., Ramdan, D. \& Djuansjah, J. R. P. Metals for biomedical applications. Biomed. Eng. - Theory Appl. (2011) doi:10.5772/19033.

12. Jena, P. K. et al. Effect of heat treatment on mechanical and ballistic properties of a high strength armour steel. Int. J. Impact Eng. 37, 242-249 (2010). 